\title{
Prescription Opioid Use among Adults with Mental Health Disorders in the United States
}

\author{
Matthew A. Davis, MPH, PhD, Lewei A. Lin, MD, Haiyin Liu, MA, and \\ Brian D. Sites, MD, MS
}

Background: The extent to which adults with mental health disorders in the United States receive opioids has not been adequately reported.

Methods: We performed a cross-sectional study of a nationally representative sample of the noninstitutionalized U.S. adult population from the Medical Expenditure Panel Survey. We examined the relationship between mental health (mood and anxiety) disorders and prescription opioid use (defined as receiving at least 2 prescriptions in a calendar year).

Results: We estimate that among the $\mathbf{3 8 . 6}$ million Americans with mental health disorders, $\mathbf{1 8 . 7 \%}$ (7.2 million of 38.6 million) use prescription opioids. Adults with mental health conditions receive 51.4\% (60 million of 115 million prescriptions) of the total opioid prescriptions distributed in the United States each year. Compared with adults without mental health disorders, adults with mental health disorders were significantly more likely to use opioids $(18.7 \%$ vs $5.0 \% ; P<.001)$. In adjusted analyses, having a mental health disorder was associated with prescription opioid use overall (odds ratio, $2.08 ; 95 \%$ confidence interval, $1.83-2.35$ ).

Conclusions: The $16 \%$ of Americans who have mental health disorders receive over half of all opioids prescribed in the United States. Improving pain management among this population is critical to reduce national dependency on opioids. (J Am Board Fam Med 2017;30:407-417.)

Keywords: Analgesics; Opioid; Anxiety Disorders; Cross-sectional Studies; Mental Health; Opioid-Related Disorders; Pain Management; Prescriptions; Surveys and Questionnaires

The United States is in the midst of an epidemic of morbidity and mortality due to prescription opioid use. ${ }^{1}$ Over the past 15 years the number of prescription opioid analgesic medications sold in the United States has quadrupled, yet the amount of pain or disability that Americans experience has remained unchanged. ${ }^{2}$ The Centers for Disease Control and Prevention reports that from 2000 to 2014, more than 165,000 people have died from

This article was externally peer reviewed.

Submitted 2 March 2017; revised 6 March 2017; accepted 10 March 2017.

From the Institute for Healthcare Policy and Innovation (MAD), the School of Nursing (MAD, HL), the Institute for Social Research (MAD), and the Addiction Center, Department of Psychiatry (LAL), University of Michigan, Ann Arbor; and the Department of Anesthesiology, Geisel School of Medicine at Dartmouth College, Hanover, NH (BDS).

Funding: none.

Conflict of interest: none declared.

Corresponding author: Matthew A. Davis, MPH, PhD, University of Michigan, 400 North Ingalls, Room 4347, Ann Arbor, MI 48109 (E-mail: mattadav@umich.edu). overdoses related to prescription opioid use. ${ }^{2}$ The identification of specific populations that rely heavily on opioids is of strategic importance for risk mitigation efforts. For instance, attention has focused on patients recovering from trauma and surgery, among whom poor coping strategies were associated with long-term reliance on opioids. ${ }^{3,4}$

Previous studies suggest that adults with mental health disorders (ie, mood and anxiety disorders) are more likely to be prescribed opioids and remain taking them long-term. ${ }^{5-8}$ For example, adults with mood disorders are nearly twice as likely to use opioids long-term for pain. ${ }^{8}$ In fact, pain is very common among adults with mental health disorders, ${ }^{9,10}$ and the relationship between mental illness and opioid use is complex. However, some suggest that mental illness may be a moderator in the relationship between pain and opioid use. ${ }^{5}$ Despite the increase in the prevalence of mental health disorders ${ }^{11}$ and the importance of tracking use of prescription opioids nationally, the extent to which 
U.S. adults with mental health disorders use prescription opioids has not been thoroughly examined. Furthermore, identification of the specific factors that may underpin the association would help clarify the complex relationship between mental health and pain.

Therefore, we used the nationally representative Medical Expenditure Panel Survey (MEPS) to examine the relationship between mental health disorders and prescription opioid use. Because anxiety and depression are the predominate mental health disorders among adults in the United States, ${ }^{11}$ we focused our attention on these 2 conditions. Our objective was to derive national estimates of opioid use among Americans with mental health disorders and to examine factors associated with such use.

\section{Methods}

We performed a cross-sectional study using nationally representative data from the MEPS, a survey of the U.S. noninstitutionalized population that is conducted by the Agency for Healthcare Research and Quality that gathers extensive information on health care utilization (including prescription medications), expenditures, and health status. ${ }^{12}$ The survey uses an overlapping panel design consisting of a household component, a medical provider component, and an insurance provider component. To avoid potential recall bias, participants are surveyed about past health and health care use at 6-month intervals. Personal and family-level data obtained from the household, medical provider, and insurance provider components are aggregated by the MEPS study team. For this study we used data from the MEPS household component files, including the full-year consolidated, medical condition, and prescription medication files. Because our study used only publically available and deidentified data, it was granted an exemption from institutional board review.

\section{Study Sample}

To increase the sample size in order to generate more stable national estimates for subgroups, we appended 2011 and 2013 MEPS data. These survey years were chosen because they were the most recently available at the time of analysis and ensured an adequate sample size. We excluded 2012 data because of duplication of participants due to the overlapping panel design (ie, aggregation of MEPS surveys in adjacent years would result in nonindependence of study participants). A total of 52,000 adults (aged $\geq 18$ years) participated in MEPS in these 2 years (25,465 in 2011 and 26,535 in 2013). After ineligible respondents were removed, such as those who were institutionalized for a period of time during the study, our final analytic sample consisted of 51,891 adults.

\section{Measures}

\section{Identification of Adults with Mental Health Disorders}

Each MEPS participant is asked to identify any health conditions in 6-month time periods. For those who have a self-reported health condition, trained MEPS staff code conditions using the International Classification of Diseases, Ninth Revision, Clinical Modification (ICD-9-CM) codes. A special feature of the MEPS is that the health care providers and facilities provide data on MEPS participants' health care use; such data are then crossreferenced with survey responses from the participant. Thus, if a person with a mental health disorder did not self-report having the condition, they would still be identified if they had a clinical diagnosis.

Based on the combination of self-report and administrative clinical data, we identified participants who had a mental health disorder. To do so we used ICD-9-CM codes truncated to the first 3 digits, including 300 (Anxiety, dissociative and somatoform disorders), 311 (Depressive disorder), and 296 (Episodic mood disorders), to identify adult MEPS participants with mental health disorders $^{13}$ (Appendix Table 1).

\section{Prescription Opioid Use}

The MEPS collects detailed data on prescription medications using a unique combination of participant self-report and administrative data obtained from pharmacies. MEPS participants are asked to supply the name of any prescribed medications and the name and location of the pharmacy where they obtained the prescription. Participants provide written permission for the release of pharmacy records. Pharmacies are contacted to obtain records, which detail the date filled, the National Drug Code, medication name, strength of the medication (amount and unit), quantity (package size), and payments by source. To identify meaningful classes of drugs, National Drug Codes are merged to the comprehensive Multum Lexicon crosswalk. ${ }^{14} \mathrm{We}$ 
used the Multum drug classes for oral "Narcotic analgesics" and "Narcotic analgesics combinations" in order to identify oral prescription opioid medications. In the MEPS prescription medication data, the most common oral opioid prescriptionswhich account for approximately $65 \%$ of all opioid prescriptions-include hydrocodone with acetaminophen, tramadol, and hydrocodone. Our study was focused on examining the likelihood of receiving prescription opioid medications rather than chronic use; thus we operationally defined an opioid user as an adult who filled $\geq 2$ prescription medications in the calendar year.

To explore the clinical diagnoses associated with prescription opioids, we also examined the top 10 clinical diagnoses for which opioids were prescribed. To collapse ICD-9-CM codes into relevant clinical disorders, the MEPS uses the Clinical Classification Software developed by the Healthcare Cost and Utilization Project. ${ }^{15}$

\section{Covariates}

We extracted a variety of health measures to be used as covariates (Appendix Table 2). The MEPS administers the 12-Item Short Form Survey (SF12) to participants. ${ }^{16}$ From these data, we calculated the mean physical component summary (PCS) and mental component summary (MCS) scores of the SF-12 (PCS and MCS scores range from 0 to 100 , with 100 indicating the highest level of health). We examined several items of the SF-12 separately as well. We collapsed self-reported health status ${ }^{17}$ into "excellent, very good, or good" versus "fair or poor." Because pain is the primary driver of prescription opioid use, we examined the SF-12 item on pain. The item inquires, "During the past 4 weeks, how much did pain interfere with your normal work (including work outside the home and housework)?" We collapsed the response set into none or little ("not at all" or "a little bit"), moderate ("moderately") or severe ("quite a bit" or "extremely"). Based on a combination of measures of both physical and cognitive limitations, we also calculated the percentage of participants with "any functional limitation," "physical limitation," "social limitation," and "cognitive limitation." We also identified those who were smokers (current vs never or former). Last, based on all medical conditions (ICD-9-CM diagnosis codes reported in the medical condition files) we generated a comorbidity score. To do so, we applied a modified version of the Charlson Comorbidity Index ${ }^{18}$ developed by D'Hoore et al. ${ }^{19}$

We used ICD-9-CM diagnosis codes 303 (Alcohol dependence syndrome), 304 (Drug dependence), and 305 (Nondependent abuse of drugs) to identify study participants with substance abuse disorders. The MEPS inquires about cancer diagnoses; we used these items to identify participants who had cancer. We also identified participants with musculoskeletal conditions using a previously applied approach. $^{20}$

From the MEPS annual consolidated files, we extracted sociodemographic data for participants in our study, including age, sex, race/ethnicity, marital status, level of education, and health insurance coverage. Age was collapsed into relevant age categories, including young adult (18-44 years), middle-aged adult (45-64 years), and older adult ( $\geq 65$ years). We also identified those adults who underwent an outpatient surgery, underwent surgery during an inpatient admission, or visited an emergency department specifically related to a physical injury.

\section{Statistical Analyses}

Our primary analyses examined the relationship between having a mental health disorder and the likelihood of prescription opioid use. We used simple descriptive measures to examine differences between adults with mental health disorders and those without, restricted to those with specific characteristics (eg, a cancer diagnosis, those selfreporting having severe pain, etc.). The $\chi^{2}$ test was used to compare proportions and an independent $t$ test was used to compare means. A 2 -sided $P$ value $<.05$ was considered statistically significant.

We used logit models to examine the relationship while adjusting for differences, and coefficients from our models were exponentiated to express associations in the form of odds ratios. Covariates in our model included age (continuous), sex, race/ ethnicity (non-Hispanic white, non-Hispanic black, Hispanic, other), health insurance coverage (private, public, uninsured), having a usual source of care, self-reported limitation due to pain (little/ none, moderate, severe), PCS score (continuous), physical limitation, substance use disorder diagnosis, outpatient surgery use, and inpatient surgery use. Because our operational definition of an opioid user was based on receiving 2 or more prescriptions in the calendar year, we also performed a sensitivity analysis in which we varied our definition to in- 
clude between 1 and 5 prescriptions and then reexamined associations.

For all analyses we used complex survey design methods to make national estimates, which account for a participant's probability of selection and sampling methodology. Because our study aggregated 2011 and 2013 MEPS data, survey weights were adjusted so that the data represented a single calendar year. Analyses were based on complete case analysis, and we assumed any missing values to be missing completely at random. Analyses were conducted using Stata MP, version 14.0 (StataCorp, College Station, TX).

\section{Results}

Among the 239.4 million U.S. adults, we estimate that 38.6 million had a mental health disorder (Table 1 and Figure 1). Of the adults with mental health disorders, $18.7 \%$ were opioid users, compared with only $5.0 \%$ among those without mental health disorders $(P<.001)$ (Figure 2). We estimate that approximately 115 million opioid prescriptions are distributed each year in the United States, $51.4 \%$ (60 million prescriptions) of which are received by adults who have a mental health disorder.

\section{Characteristics of Adults with a Mental Health Disorder Who Use Opioids}

Among adults with mental health disorders, opioid users differed in several ways. Opioid users were older (nearly $75 \%$ of opioid users were aged $\geq 45$ years compared with $60 \%$ among nonopioid users), more likely to be non-Hispanic white, and completed less educational $(P<.001$ for all $)$ (Table 1$)$. Comparing opioid users with and without a mental health disorder, those with a mental health disorder were more likely to be middle-aged, female, nonHispanic white, and divorced, separated, or widowed.

Among adults with mental health disorders, opioid users were considerably less healthy than nonopioid users (Table 1 and Appendix Table 2). The mean PCS score was 33.5 (standard error, 0.50) among opioid users versus 47.7 (standard error, $0.20)$ among nonopioid users $(P<.001)$. Likewise, among adults with mental health disorders, opioid users had considerably more comorbidities; for instance, $18.1 \%$ of opioid users had $\geq 3$ comorbidities, compared with just $6.3 \%$ among nonopioid users. Adults with mental health disorders who use opioids also had much higher self-reported pain levels (eg, $60.0 \%$ of opioid users reported severe pain compared with only $16.2 \%$ among nonopioid users). Among opioid users, those with mental health disorders were less healthy than those without mental health disorders, but the differences were less pronounced.

\section{Opioid Use Among Adults with Mental Health Disorders}

Among specific subpopulations based on the level of self-reported pain, cancer diagnosis, and musculoskeletal conditions, the higher percentage of opioid users persisted among adults with mental health conditions compared with those without $(P<.001$ for all) (Figure 2). Most notable was nearly twice the percentage of opioid users among adults with severe pain $(45.3 \%$ of adults with mental health disorders were opioid users compared with $24.1 \%$ among those without mental health disorders).

The top 10 clinical diagnoses associated with prescription opioids for Americans with mental health disorders included musculoskeletal disorders, poorly defined conditions, or an otherwise missing diagnosis (Figure 3). The top 10 clinical diagnoses we identified among adults with mental health disorders account for $54.0 \%$ of the total opioids prescribed to this population, suggesting considerable variation in clinical diagnosis.

\section{Association Between Mental Health Disorders and Opioid Use}

In unadjusted analyses the odds of opioid use was $>4$ times higher among adults with mental health disorders than among those without (odds ratio $[\mathrm{OR}], 4.34$; 95\% confidence interval [CI], 3.934.77) (Table 2). After adjusting for sociodemographic characteristics, health status, and use of selected health services, although attenuated, the association persisted: adults with mental health disorders had more than twice the odds of being an opioid user (OR, 2.08; 95\% CI, 1.83-2.35). Other notable factors in the fully adjusted model associated with opioid use included having a usual source of care (OR, 1.67), having moderate or severe selfreported pain (ORs , 2.15 and 3.15, respectively), reporting a physical limitation (OR, 1.84), having had surgery (ORs, 2.73 and 3.58 for outpatient and inpatient surgery, respectively), and having a substance abuse diagnosis (OR, 2.42). 
Table 1. Sociodemographic Characteristics and Health Status of U.S. Adults According to Mental Health Disorder Status and Opioid Use

\begin{tabular}{|c|c|c|c|c|c|c|}
\hline & \multicolumn{2}{|c|}{ No Mental Health Disorder } & \multicolumn{2}{|c|}{ Mental Health Disorder } & \multirow[b]{2}{*}{$P$ Value* } & \multirow[b]{2}{*}{$P$ Value } \\
\hline & $\begin{array}{l}\text { Non-Opioid User } \\
\quad(\mathrm{n}=42,908)\end{array}$ & $\begin{array}{l}\text { Opioid User } \\
(\mathrm{n}=1,983)\end{array}$ & $\begin{array}{l}\text { Non-Opioid User } \\
\quad(\mathrm{n}=5,690)\end{array}$ & $\begin{array}{l}\text { Opioid User } \\
(\mathrm{n}=1,310)\end{array}$ & & \\
\hline No. of U.S. adults, millions & 190.7 & 10.1 & 31.4 & 7.2 & & \\
\hline \multicolumn{7}{|l|}{ Sociodemographic characteristics } \\
\hline Age, years & & & & & $<.001$ & $<.001$ \\
\hline $18-44$ & 49.4 & 29.7 & 40.0 & 25.1 & & \\
\hline $45-64$ & 32.7 & 42.0 & 39.8 & 51.9 & & \\
\hline$\geq 65$ & 17.9 & 28.3 & 20.3 & 22.9 & & \\
\hline Sex & & & & & .14 & $<.001$ \\
\hline Male & 51.2 & 45.8 & 34.8 & 32.2 & & \\
\hline Female & 48.8 & 54.2 & 65.2 & 67.8 & & \\
\hline Race/ethnicity & & & & & .03 & $<.001$ \\
\hline Non-Hispanic white & 62.8 & 74.1 & 79.3 & 80.6 & & \\
\hline Non-Hispanic black & 12.2 & 13.5 & 7.1 & 8.2 & & \\
\hline Hispanic & 16.5 & 8.7 & 9.4 & 6.8 & & \\
\hline Other or multiple races & 8.4 & 3.7 & 4.1 & 4.5 & & \\
\hline Marital status & & & & & $<.001$ & $<.001$ \\
\hline Married & 53.4 & 55.1 & 46.8 & 44.9 & & \\
\hline $\begin{array}{l}\text { Divorced, separated, or } \\
\text { widowed }\end{array}$ & 17.9 & 28.4 & 27.6 & 40.3 & & \\
\hline Never married & 28.7 & 16.5 & 25.5 & 14.9 & & \\
\hline Education & & & & & $<.001$ & .06 \\
\hline High school or less & 56.3 & 63.5 & 53.9 & 67.9 & & \\
\hline $\begin{array}{l}\text { Some college or bachelor's } \\
\text { degree }\end{array}$ & 27.5 & 25.8 & 28.2 & 24.5 & & \\
\hline Advanced degree & 16.2 & 10.7 & 17.9 & 7.6 & & \\
\hline Health insurance & & & & & $<.001$ & $<.001$ \\
\hline Private & 67.9 & 60.5 & 65.8 & 47.1 & & \\
\hline Public & 15.8 & 30.7 & 23.4 & 45.7 & & \\
\hline Uninsured & 16.3 & 8.7 & 10.8 & 7.2 & & \\
\hline \multicolumn{7}{|l|}{ Health status } \\
\hline \multicolumn{7}{|l|}{ SF-12, mean (SE) } \\
\hline PCS score & $50.9(0.08)$ & $37.8(0.47)$ & $47.7(0.20)$ & $33.5(0.50)$ & $<.001$ & $<.001$ \\
\hline MCS score & $53.1(0.06)$ & $49.6(0.32)$ & $43.9(0.20)$ & $40.6(0.40)$ & $<.001$ & $<.001$ \\
\hline Fair or poor overall health & 8.8 & 32.2 & 21.0 & 54.3 & $<.001$ & $<.001$ \\
\hline Number of comorbidities & & & & & $<.001$ & $<.001$ \\
\hline 0 & 89.0 & 72.8 & 78.3 & 58.2 & & \\
\hline $1-2$ & 7.9 & 15.9 & 15.4 & 23.7 & & \\
\hline$\geq 3$ & 3.1 & 11.3 & 6.3 & 18.1 & & \\
\hline
\end{tabular}

Data are percentages unless otherwise indicated. All estimates are weighted to represent the U.S. noninstitutionalized population. The $\chi^{2}$ test was used to compare proportions.

${ }^{*} P$ value compares nonopioid users with opioid users among adults with mental health disorders.

${ }^{\dagger} P$ value compares adult opioid users with versus those without mental health disorders.

MCS, mental component summary; PCS, physical component summary; SE, standard error; SF-12, 12-item Short Form.

In our sensitivity analyses, all associations persisted when varying our opioid user definition (from 1 to 5 prescriptions/year), and were more pronounced with more stringent definitions of opioid use.

\section{Discussion}

Although, previous reports have documented the association between having a mental health disorder and opioid use in specific populations, our 
Figure 1. Estimated number of adults with mental health disorders who use prescription opioids in the United States. All estimates are weighted to represent the U.S. noninstitutionalized population.

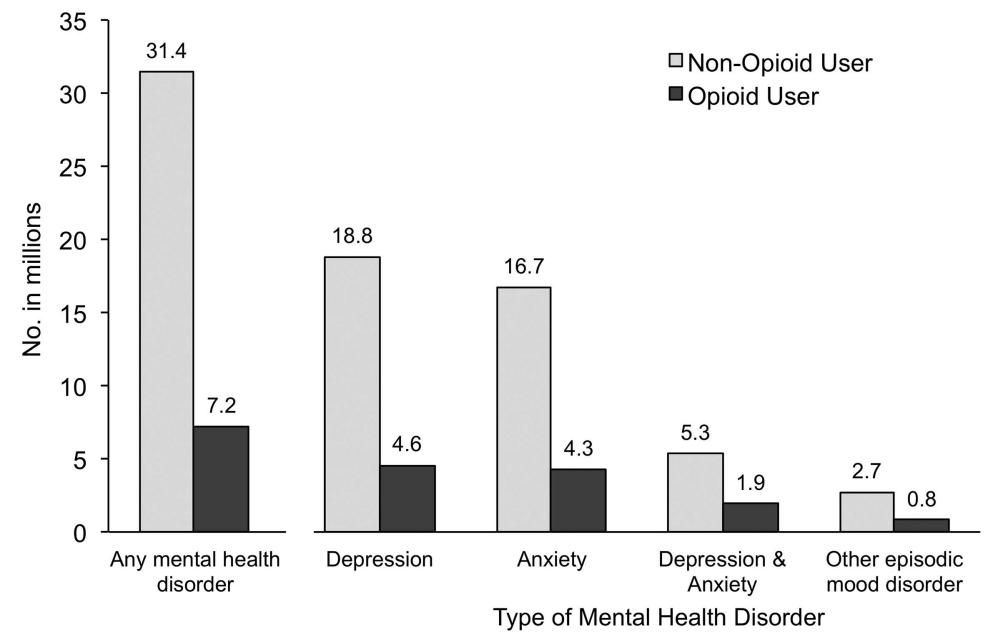

study offers several contributions. First, we found that the population of adults with mental health disorders receive more than half of the total opioid prescriptions in the United States. Second, among the nearly 40 million Americans who have a mental health condition, approximately $19 \%$ use prescription opioids. Last, higher opioid use among those with mental health disorders persists across key characteristics, including cancer status and various levels of self-reported pain.

Although evidence-based prescribing guidelines are emerging, ${ }^{21,22}$ there exists a complex interaction of factors related to the patient, provider, and medical and social conditions that ultimately results in the decision to prescribe an opioid. ${ }^{23}$ Our findings that patients with mental illness are more likely to receive opioid prescriptions across all different levels of pain suggests that there may be additional patient- and provider-related factors specific to those with mental illness that increase the likelihood of receiving prescription opioids. Such a relationship is particularly concerning because mental illness is also a prominent risk factor for overdose and other adverse opioid-related outcomes. $^{24,25}$ Thus, the expectation would be that physicians would be more conservative with their prescribing behaviors in the setting of mental illness and favor nonopioid alternatives. The ability

Figure 2. Estimated percentages of U.S. adults with and without mental health disorders who use prescription opioids, according to selected characteristics. All estimates are weighted to represent the U.S. noninstitutionalized population. Error bars represent 95\% confidence intervals. Musculoskeletal conditions include all forms of arthritis, and other pain-related conditions.

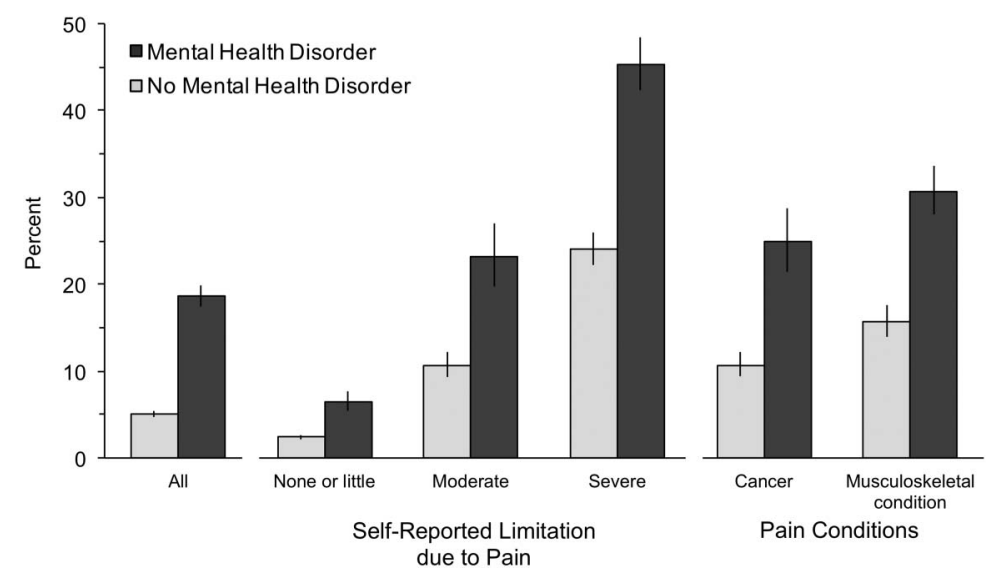


Figure 3. Top 10 clinical diagnoses for prescription opioids among U.S. adults who have a mental health disorder. All estimates are weighted to represent the number of prescriptions among the U.S. noninstitutionalized population. The $\chi^{2}$ test was used to compare proportions.

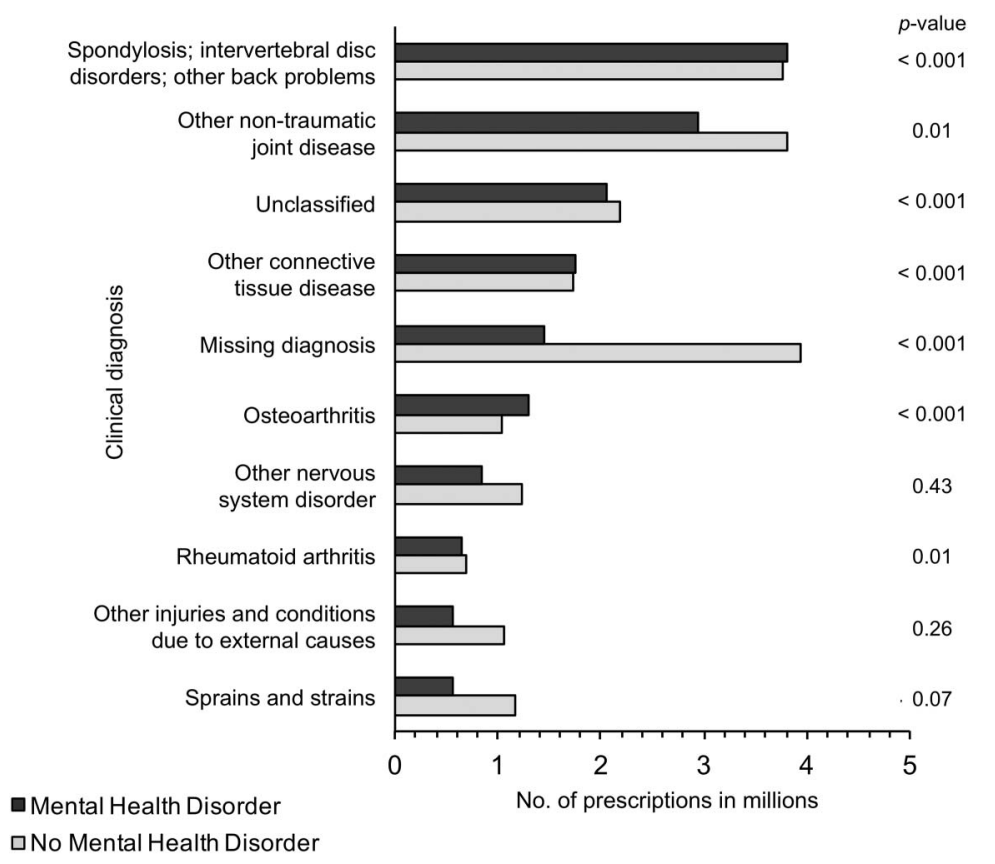

to identify populations that may use prescription opioids independent of pain would be of strategic importance for mitigating potential risk at a population health level.

The challenge with pain management is that there is no biological measure of pain or objective assessment of efficacy of treatment. The International Association for the Study of Pain adopted a definition of pain that is widely accepted. ${ }^{26}$ The definition states that pain is "an unpleasant sensory and emotional experience, associated with actual or threatened tissue damage, or described in terms of such." The definition thus relies on physician interpretation and the subjective experience of the patient. Thus, one could hypothesize that increased opioid use in patients with mental health disorders may be related to a variety of psychological factors that may contribute to an increased subjective experience of pain or to increased likelihood of using opioids irrespective of pain level. ${ }^{5}$

Our finding that approximately $19 \%$ of adults with mental health disorders use prescription opioids aligns with what is to our knowledge the only other article that used nationally representative data to examine this relationship. Halbert and colleagues ${ }^{8}$ examined patients with pain-related conditions and found those who had mood disorders were more likely to initiate opioid use than those without mood disorders: $19.3 \%$ of patients with pain and mood disorders initiated opioid use, compared with $17.2 \%$ of patients with pain without mood disorders. Evidence indicating an increased risk of depressive symptoms in patients receiving chronic opioids may raise concerns regarding reverse causality. ${ }^{27}$ The relationship between mental health disorders and pain is also likely bidirectional, with improvements in pain leading to improvements in mental health symptoms and vice versa. ${ }^{28}$ Furthermore, some evidence indicates that optimizing depression and pain treatment can improve outcomes in both areas for patients seen in primary care. ${ }^{29}$ Although the relationship between mental health disorders, pain, and opioid use is complex, we found that having a mental health disorder is associated with increased opioid use even after controlling for a wide array of other demographic and clinical risk factors, including substance abuse. The high prevalence of mental health disorders coupled with prescription opioid use suggests that this population is critical to consider when addressing the issue of opioid use from a health system or policy perspective. Although a number of important steps are already underway to address opioid use in this country, such as the 
Table 2. Odds Ratios For the Association Between Independent Factors and Prescription Opioid Use

\begin{tabular}{|c|c|c|}
\hline \multirow[b]{2}{*}{ Independent Variables } & \multicolumn{2}{|c|}{ Odds Ratio (95\% CI) } \\
\hline & Unadjusted & Adjusted* \\
\hline Any mental health disorder & $4.34(3.93-4.77)$ & $2.08(1.83-2.35)$ \\
\hline Age, years & $1.02(1.02-1.02)$ & $0.99(0.98-1.00)$ \\
\hline \multicolumn{3}{|l|}{ Sex } \\
\hline Male & 1.00 (Reference) & 1.00 (Reference) \\
\hline Female & $1.42(1.31-1.55)$ & $1.07(0.96-0.99)$ \\
\hline \multicolumn{3}{|l|}{ Race/ethnicity } \\
\hline Non-Hispanic white & 1.00 (Reference) & 1.00 (Reference) \\
\hline Non-Hispanic black & $0.83(0.74-0.93)$ & $0.80(0.70-0.91)$ \\
\hline Hispanic or Latino & $0.43(0.38-0.49)$ & $0.58(0.49-0.67)$ \\
\hline Other & $0.44(0.35-0.56)$ & $0.55(0.42-0.72)$ \\
\hline \multicolumn{3}{|l|}{ Health insurance coverage } \\
\hline Private & 1.00 (Reference) & 1.00 (Reference) \\
\hline Public & $2.70(2.44-3.00)$ & $1.23(1.06-1.42)$ \\
\hline Uninsured & $0.64(0.54-0.76)$ & $0.86(0.70-1.06)$ \\
\hline Has usual source of care & $2.91(2.49-3.39)$ & $1.67(1.39-2.02)$ \\
\hline PCS score & $0.91(0.91-0.91)$ & $0.96(0.95-0.97)$ \\
\hline \multicolumn{3}{|l|}{ Self-reported overall health status } \\
\hline Excellent to good & 1.00 (Reference) & 1.00 (Reference) \\
\hline Fair or poor & $6.02(5.38-6.74)$ & $1.29(1.11-1.48)$ \\
\hline \multicolumn{3}{|c|}{ Self-reported limitation due to pain } \\
\hline None or little & 1.00 (Reference) & 1.00 (Reference) \\
\hline Moderate & $5.25(4.50-6.13)$ & $2.15(1.78-2.59)$ \\
\hline Severe & $15.24(13.41-17.31)$ & $3.15(2.58-3.85)$ \\
\hline Physical limitation & $8.25(7.40-9.20)$ & $1.84(1.56-2.17)$ \\
\hline Has substance abuse diagnosis & $4.29(2.88-6.40)$ & $2.42(1.19-4.96)$ \\
\hline Had outpatient surgery & $4.62(3.98-5.36)$ & $2.73(2.22-3.36)$ \\
\hline Had inpatient surgery & $7.02(6.13-8.05)$ & $3.58(2.92-4.38)$ \\
\hline
\end{tabular}

All estimates are weighted to represent the U.S. noninstitutionalized population.

*Adjusted for all other factors in the table.

PCS, physical component summary.

recent Centers for Disease Control and Prevention opioid prescribing guidelines, ${ }^{22}$ improving treatment of comorbid mental health disorders and pain will be an important focus when trying to reduce the overall negative impacts of opioid use on patients and communities.

\section{Study Limitations}

Our study has several limitations that must be acknowledged. First, our study used a cross-sectional, observational design and therefore is not intended to demonstrate a cause-effect relationship between having a mental health disorder and using opioids. Thus we cannot rule out the effects of residual confounding nor potential reverse causality. However, with regard to the latter, recent evidence from longitudinal analyses suggests opioid-naïve patients with mood disorders are in fact more likely to initiate prescription opioids and to transition to longer-term opioid use than those without a mood disorder. ${ }^{8}$ Second, because we focused on determining whether clinical treatment varies by mental health disorder status, our study only examined prescription opioid use and therefore neglects any concurrent illicit medication use. Third, we investigated the association between mental health disorders and opioid use among noninstitutionalized U.S. adult citizens. Therefore, findings among children or institutionalized adults may differ. Last, the MEPS data on health care utilization and expenditures are self-reported by patients, potentially causing inaccuracies; however, the MEPS attempts to correct self-reported errors by verify- 
ing response data with the participant's health care and insurance providers.

Despite these inherent limitations, our study offers valuable insights regarding opioid use among Americans with mental health disorders. Although the relationship between mental health and pain management is complex, we find that as a population, adults with mental health disorders receive more than half of all opioid prescriptions distributed each year in the United States. This finding warrants more research to understand further the association between mental health disorders and prescription opioid use, and to promote safer opioid use among this population.

To see this article online, please go to: bttp://jabfm.org/content/ 30/4/407.full.

\section{References}

1. Centers for Disease Control and Prevention. 2011. Understanding the epidemic: drug overdose deaths in the United States continue to increase in 2015. Updated December 16, 2016. Available from: http:// www.cdc.gov/drugoverdose/epidemic/. Accessed December 15, 2016.

2. Rudd RA, Aleshire N, Zibbell JE, Gladden RM. Increases in drug and opioid overdose deaths-United States, 2000-2014. MMWR Morb Mortal Wkly Rep 2016;64:1378-82.

3. Helmerhorst GT, Vranceanu AM, Vrahas M, Smith M, Ring D. Risk factors for continued opioid use one to two months after surgery for musculoskeletal trauma. J Bone Joint Surg Am 2014;96:495-9.

4. Inacio MC, Hansen C, Pratt NL, Graves SE, Roughead EE. Risk factors for persistent and new chronic opioid use in patients undergoing total hip arthroplasty: a retrospective cohort study. BMJ Open 2016; 6:e010664.

5. Goesling J, Henry MJ, Moser SE, et al. Symptoms of depression are associated with opioid use regardless of pain severity and physical functioning among treatment-seeking patients with chronic pain. J Pain 2015;16:844-51.

6. Sullivan MD, Edlund MJ, Zhang L, Unutzer J, Wells KB. Association between mental health disorders, problem drug use, and regular prescription opioid use. Arch Intern Med 2006;166:2087-93.

7. Seal KH, Shi Y, Cohen G, et al. Association of mental health disorders with prescription opioids and high-risk opioid use in US veterans of Iraq and Afghanistan. JAMA 2012;307:940-7.

8. Halbert BT, Davis RB, Wee CC. Disproportionate longer-term opioid use among U.S. adults with mood disorders. Pain 2016;157:2452-7.
9. Bair MJ, Robinson RL, Katon W, Kroenke K. Depression and pain comorbidity: a literature review. Arch Intern Med 2003;163:2433-45.

10. Currie SR, Wang J. Chronic back pain and major depression in the general Canadian population. Pain 2004;107:54-60.

11. Centers for Disease Control and Prevention. Burden of mental illness. Last reviewed July 1, 2011; last updated October 4, 2013; Available from: https:// www.cdc.gov/mentalhealth/basics/burden.htm. Accessed September 15, 2016.

12. Cohen JW, Cohen SB, Banthin JS. The Medical Expenditure Panel Survey: a national information resource to support healthcare cost research and inform policy and practice. Med Care 2009;47 (7 Suppl 1):S44-50.

13. Guevara JP, Mandell DS, Rostain AL, Zhao H, Hadley TR. National estimates of health services expenditures for children with behavioral disorders: an analysis of the medical expenditure panel survey. Pediatrics 2003;112(6 Pt 1):e440.

14. Cerner Corporation. Cerner Multum drug database. Available from: http://www.cerner.com/cerner multum/. Accessed December 15, 2016.

15. Agency for Healthcare Research and Quality. Healthcare Utilization Project. Clinical Classification Software for ICD-9-CM. Last modified March 6, 2017. Available from: https://www.hcup-us. ahrq.gov/toolssoftware/ccs/ccs.jsp. Accessed December 15, 2016.

16. Ware J Jr, Kosinski M, Keller SD. A 12-item ShortForm Health Survey: construction of scales and preliminary tests of reliability and validity. Med Care 1996;34:220-33.

17. DeSalvo KB, Bloser N, Reynolds K, He J, Muntner P. Mortality prediction with a single general selfrated health question. A meta-analysis. J Gen Intern Med 2006;21:267-75.

18. Charlson ME, Pompei P, Ales KL, MacKenzie CR. A new method of classifying prognostic comorbidity in longitudinal studies: development and validation. J Chronic Dis 1987;40:373-83.

19. D'Hoore W, Bouckaert A, Tilquin C. Practical considerations on the use of the Charlson Comorbidity Index with administrative data bases. J Clin Epidemiol 1996;49:1429-33.

20. Gaskin DJ, Richard P. The economic costs of pain in the United States. J Pain 2012;13:715-24.

21. Chou R, Gordon DB, de Leon-Casasola OA, et al. Management of postoperative pain: a clinical practice guideline from the American Pain Society, the American Society of Regional Anesthesia and Pain Medicine, and the American Society of Anesthesiologists' Committee on Regional Anesthesia, Executive Committee, and Administrative Council. J Pain 2016;17:131-57. 
22. Dowell D, Haegerich TM, Chou R. CDC Guideline for prescribing opioids for chronic pain-United States, 2016. JAMA 2016;315:1624-45.

23. Turk DC, Okifuji A. What factors affect physicians' decisions to prescribe opioids for chronic noncancer pain patients? Clin J Pain 1997;13:330-6.

24. Cochran BN, Flentje A, Heck NC, et al. Factors predicting development of opioid use disorders among individuals who receive an initial opioid prescription: mathematical modeling using a database of commercially-insured individuals. Drug Alcohol Depend 2014;138:202-8.

25. Park TW, Lin LA, Hosanagar A, Kogowski A, Paige $\mathrm{K}$, Bohnert AS. Understanding risk factors for opioid overdose in clinical populations to inform treatment and policy. J Addict Med 2016;10:369-81.
26. Task Force on Taxonomy of the International Association for the Study of Pain. Classification of Chronic Pain. Seattle (WA): IASP Press; 1994.

27. Scherrer JF, Salas J, Copeland LA, et al. Increased risk of depression recurrence after initiation of prescription opioids in noncancer pain patients. J Pain 2016;17:473-82.

28. Kroenke K, Wu J, Bair MJ, Krebs EE, Damush TM, $\mathrm{Tu} W$. Reciprocal relationship between pain and depression: a 12-month longitudinal analysis in primary care. J Pain 2011;12:964-73.

29. Kroenke K, Bair MJ, Damush TM, et al. Optimized antidepressant therapy and pain self-management in primary care patients with depression and musculoskeletal pain: a randomized controlled trial. JAMA 2009;301:2099-110. 
Appendix Table 1. Medical Expenditure Panel Survey Participants with Mental Health Disorders According to International Classification of Diseases, Ninth Revision, Clinical Modification Diagnosis Codes

\begin{tabular}{clc}
\hline ICD-9-CM Code & \multicolumn{1}{c}{ Description } & Participants with Code, n (\% among adults) \\
\hline 296 & Episodic mood disorders & $671(1.3)$ \\
300 & Anxiety, dissociative, and somatoform disorders & $3,644(7.0)$ \\
311 & Depressive disorder & $4,362(8.4)$ \\
\hline
\end{tabular}

ICD-9-CM, International Classification of Disease, Ninth Revision, Clinical Modification.

Appendix Table 2. Health Status of U.S. Adults According to Mental Health Disorder Status and Opioid Use

\begin{tabular}{|c|c|c|c|c|c|c|}
\hline & \multicolumn{2}{|c|}{ No Mental Health Disorder } & \multicolumn{2}{|c|}{ Mental Health Disorder } & \multirow[b]{2}{*}{$P$ Value* } & \multirow[b]{2}{*}{$P$ Value $^{\dagger}$} \\
\hline & $\begin{array}{l}\text { Non-Opioid User } \\
\quad(\mathrm{n}=42,908)\end{array}$ & $\begin{array}{l}\text { Opioid User } \\
(\mathrm{n}=1,983)\end{array}$ & $\begin{array}{l}\text { Non-Opioid User } \\
\quad(\mathrm{n}=5,690)\end{array}$ & $\begin{array}{l}\text { Opioid User } \\
(\mathrm{n}=1,310)\end{array}$ & & \\
\hline \multicolumn{7}{|l|}{ Health status } \\
\hline \multicolumn{7}{|l|}{ SF-12, mean (SE) } \\
\hline PCS score & $50.9(0.08)$ & $37.8(0.47)$ & $47.7(0.20)$ & $33.5(0.50)$ & $<.001$ & $<.001$ \\
\hline MCS score & $53.1(0.06)$ & $49.6(0.32)$ & $43.9(0.20)$ & $40.6(0.40)$ & $<.001$ & $<.001$ \\
\hline Fair or poor overall health & 8.8 & 32.2 & 21.0 & 54.3 & $<.001$ & $<.001$ \\
\hline Self-reported limitation due to pain & & & & & $<.001$ & $<.001$ \\
\hline None or little & 84.6 & 40.2 & 69.4 & 21.2 & & \\
\hline Moderate & 8.6 & 19.6 & 14.4 & 18.9 & & \\
\hline Severe & 6.8 & 40.2 & 16.2 & 60.0 & & \\
\hline Smoker & 15.2 & 24.9 & 22.4 & 36.7 & $<.001$ & $<.001$ \\
\hline Number of comorbidities & & & & & $<.001$ & $<.001$ \\
\hline 0 & 89.0 & 72.8 & 78.3 & 58.2 & & \\
\hline $1-2$ & 7.9 & 15.9 & 15.4 & 23.7 & & \\
\hline$\geq 3$ & 3.1 & 11.3 & 6.3 & 18.1 & & \\
\hline \multicolumn{7}{|l|}{ Self-reported limitation } \\
\hline Any self-reported limitation & 19.6 & 61.2 & 42.7 & 81.2 & $<.001$ & $<.001$ \\
\hline Physical limitation & 8.3 & 40.1 & 21.0 & 59.3 & $<.001$ & $<.001$ \\
\hline Social limitation & 2.8 & 18.7 & 11.7 & 36.0 & $<.001$ & $<.001$ \\
\hline Cognitive limitation & 2.7 & 11.3 & 13.6 & 30.9 & $<.001$ & $<.001$ \\
\hline \multicolumn{7}{|l|}{ Healthcare use } \\
\hline Has usual source of care & 71.0 & 86.8 & 85.0 & 91.3 & $<.001$ & $<.01$ \\
\hline Had inpatient surgery & 2.9 & 18.2 & 4.2 & 18.0 & $<.001$ & .93 \\
\hline Had outpatient surgery & 3.6 & 17.5 & 6.1 & 13.7 & $<.001$ & .04 \\
\hline Had at least one ED visit for injury & 15.3 & 41.5 & 25.1 & 43.5 & $<.001$ & .38 \\
\hline
\end{tabular}

Data are percentages unless otherwise indicated. All estimates are weighted to represent the U.S. noninstitutionalized population. The $t$ test was used to compare means, and the $\chi^{2}$ test was used to compare proportions.

${ }^{*} P$ value compares non-opioid users with opioid users among adults with mental health disorders.

${ }^{\dagger} P$ value compares adult opioid users with versus those without mental health disorders.

ED, emergency department; MCS, mental component summary; PCS, physical component summary; SE, standard error; SF-12, 12-item Short Form. 